\title{
The Post-COVID-19 Future: State Capability in Ensuring Shared Prosperity
}

\author{
Yan Vaslavskiy a and Irina Vaslavskaya ${ }^{\mathrm{b}}$
}

\begin{abstract}
The coronavirus (COVID-19) pandemic has caused profound upheavals in national communities, from humanitarian disasters to unprecedented economic downturns. All the consequences of COVID-19 have made it necessary to understand the reasons for state inefficiency and its traditional functions of ensuring economic balance and financial stability in the period before COVID-19. In fact, inefficiency is a fundamental problem of modern socioeconomic systems. Only a violation of societal integrity can explain why economic isolation and social distancing managed to instantly destroy economic structures, cause a loss in confidence in governments by citizens and increase the potential for protest against the extraordinary actions of nation-states in the fight against COVID-19. At the end of 2020, there was universal agreement about a fundamentally uncertain post-COVID-19 reality. Many progressive specialists have expressed the opinion that the degree of future socioeconomic progress directly depends on the abilities of policymakers to prioritise societal integrity in solving economic problems and achieving the goal of shared prosperity in the future.
\end{abstract}

Keywords: Social fault lines; Triangle dilemma of Musgrave; Societal crisis; State inefficiency; Epinomic policy.

JEL Classification: B41, E20, E60, E62, H69

a Department of Political Theory, Moscow State Institute for Foreign Relations (MGIMO University), Moscow, Russian Federation. Email: vaslavsky@yandex.ru, y.vaslavskiy@inno. mgimo.ru, Orcid ID: 0000-0003-0707-1699

b Corresponding author. Department of Economics of Enterprises and Organizations, Higher School of Economics and Rights, Kazan Federal University, Naberezhnye Chelny Institute, Russian Federation. Email: vaslavskaya@yandex.ru, IJVaslavskaya@kpfu.ru, Orcid ID: 0000$0002-1363-3865$ 


\section{Introduction}

Before the COVID-19 pandemic, the number of publications devoted to the problems of slowing economic growth and deepening social fault lines had already increased (Rajan, 2010; Milanovic, 2019; Haskel \& Westlake, 2017). At the same time, state behaviour was analysed using, for example, growing budget expenditures which exceeded their income bases and increased the current budget deficits. This was objectively connected to an increase in public debt, which in the bulk of the developed countries began to exceed gross domestic product (GDP). The arguments in support of the above points of view were based on prioritising the economy to solve all national problems, including social ones. As a result, it followed logically that with the growth of GDP, an increasing share of GDP could be spent on reducing social "fault lines" in national communities, where once things "were bad", but now "they are getting better". The mechanistic nature of this conclusion and the complete inconsistency of such an approach to understanding individual values in the formation of social integrity clearly manifested during the period of exponential spread of the COVID-19 pandemic and the increasing lethality of cases.

Emergency measures taken by nation-states all over the globe have come to be associated with unexpected measures taken to impose economic isolation and social distancing Although the state, in this case, has clearly defended human lives, and unprecedented fiscal measures were aimed at ensuring livelihoods, this did not cause the unification of all citizen efforts. This "fault line" between citizens and the state resulted in numerous protests against the policies of the national government, which interrupted work and restricted communication - both at workplaces and in the field of entertainment, tourism and other social contacts - predetermined by the loss of citizen confidence in their state. And in conditions of social disunity, practically no national problem can be solved. In other words, an uncertain future has already arrived, but no one has noticed it.

The main characteristic of this future reality is its uncertainty. Almost everyone is unanimous in agreeing that this "new normal" will be radically different from previous norms before the pandemic (Georgieva, 2020; Sneader \& Singhal, 2021). Nevertheless, judging by fiscal forecasts prepared by International Monetary Fund (IMF) experts, it is possible to conclude that everything is changing, but not public finance. By 2024, the budgetary 
expenditures of nation-states are projected to reach the level of 2019 GDP shares and budget deficits, i.e., returning to fiscal priorities that revealed the ineffectiveness of the state even before COVID-19 (IMF, January 2021). In addition, the latest data on the state of the global economy, prepared by experts from PricewaterhouseCoopers (PwC) and IMF, indicate that no dramatic growth rates are anticipated until 2027 (Kupelian \& Clarry, 2021). As a result, with relatively low average GDP growth rates and a reduction in the share of fiscal spending, it is difficult to imagine the likelihood of a reduction in "social fault lines" in national communities post-COVID-19, which leads to the growing distrust of citizens in the state (IPSOS, 2021). Under these conditions, it is hardly possible to construct a fundamentally new post-COVID-19 reality in the foreseeable future.

National governments must be proactive (ex ante), but they are accustomed to react to happenings ex post. Post-COVID-19, each national government will be forced to independently decide on the future realities for their countries. And those who intuitively understand changed priorities and connect them faster to social cohesion and the reduction of social "fault lines" will be the first to orient budget spending towards the main spheres of people's lives - health and education. In doing so, they will ensure rapid progress and shared prosperity. The Russian philosopher Berdyaev once: "The state does not exist to transform earthly life into paradise, but in order to prevent it from turning into hell" (quoted in Tanzi, 2011: 19). The political capabilities of the state in restoring the integrity of society, as the basis for the acceleration of technological and economic progress, will depend on how quickly and how far the state moves away from "prevent[ing] it from turning into hell", which is happening to the most disadvantaged part of the population.

We begin with a literature review on the problems of the state in terms of its fundamental functions before COVID-19, and changes in connection with the pandemic. Further, there is a comparative analysis of theoretical approaches to the problems of the effectiveness of state activities in fighting COVID-19. Particular attention is paid to the special relationship between the above problems in the phenomenon of "secular stagnation" in the 2000s and the orientation of nation-states towards financial stability.

The next section substantiates the peculiarity of structural changes in national economies, from the standpoint of the dialectic interaction between the state and society. For this purpose, an analysis of the growth 
rates of GDP, budget expenditures and revenues is carried out, in which we determine that the redistribution of GDP lies with the government, with the most significant impact on the processes of economic development. In this regard, the most acceptable instrument for analysis is the "magic triangle" proposed by Musgrave (1998). The angles of this triangle conventionally represent the main groups of functions of the state, concretised by its main budgetary expenditures. Then we used the Musgrave uncertainty principle (Pilipenko \& Pilipenko, 2020), which allows us, by indirect signs, to single out the main dialectical contradiction in national communities, the one which disrupts the interactions between the state and society and negatively affects the efficiency of the state. The virtual inability of national governments to confront the humanitarian disaster is an example of such indirect evidence. The above approach enables us to draw an analogy between the ineffectiveness of the state before COVID and the opportunities missed by society because of the pandemic.

The results and discussion suggest the acceptability of the Musgrave triangle in modelling post-COVID-19 reality, provided that the state can restore the dialectic interrelation between society and economy and ensure universal prosperity.

\section{The Nation-State and its Traditional Functions}

For a long time, Keynes's (1936) views were considered unshakable. State policy was about stabilising the national economy, ensuring a balance of savings and investments and ensuring "full employment" in the economic system. But the development of national economies means that modern states bear much more responsibilities to society than Keynes (1936) assumed. Even today, this interpretation of the state remains prevalent, according to which its importance to society undoubtedly increases over time, but the effectiveness of its activities does not matter. In other words, until COVID-19, the approach used by Musgrave (1959) remain relevant. According to him, the main obligations of the state to society are: (1) the allocation of resources; (2) economic stabilisation (the principle of economic efficiency); and (3) the redistribution of income (the principle of social justice). This list does not include providing market circulation in the economy with the help of formal institutions that help to reduce transaction costs or providing unconditional fulfilment of partners' obligations. 
The state cannot completely perform all these functions due to budgetary constraints. Musgrave (1998) considered it possible to solve this problem by presenting these functions of the state through budget expenditures. Thus, the three main functions of the state and the corresponding budget expenses were reduced to his "triangle dilemma". The essence of the dilemma is that only two of the functions, in principle, can be fully financed at any given period. First, financing is impeded by the state's fiscal constraints, as predetermined by its chronic budget deficit. Second, Musgrave (1959) argued that simultaneous effective performance was, in principle, impossible.

The logic of these contradictory interactions is reproduced in Table 1, by analogy with Pilipenko and Pilipenko (2020). It should be noted that theoretically, the groups of functions, designated A and B in the triangle dilemma, can be implemented more or less successfully at different time periods. For example, ensuring a fair distribution of income (in compliance with the principle of social justice) is difficult to implement simultaneously with the other two, if all other conditions remain unchanged. However, if economic parameters grow fast enough, then the material security of the low-income strata increases and thus, social justice is realised. So, before COVID-19, the economic assessment of social inequalities dominated. But inequality did not change: if the material level of all segments of the population increased, then the polarisation of income only increased. The situation was aggravated by the fact that when economic processes slowed down, budgetary spending on social needs was carried out according to the residual principle (Cingano, 2014). Thus, an important consequence of the triangle dilemma is setting fiscal priorities in planning and performing public functions at any given time (Tanzi, 2011), manifesting in the impossibility of simultaneously achieving effectiveness in all the functions of nationstates (Musgrave, 1998), fully consistent with the fundamental dilemma that "macroeconomic stability [means] social equality (justice)" (Okun, 2015).

Thus, it becomes possible to explain the further logic of the fiscal priorities of nation-states. They unambiguously prioritised economic stability since the end of the $20^{\text {th }}$ century, thereby indirectly confirming the secondary importance of social justice and (fair) redistribution of income, which largely explains the residual principle of budgetary financing. A priori, both theorists and practitioners began to realise that solving economic problems (by accelerating economic growth and per capita real GDP) would serve as a real basis for levelling "fault lines" in society. It should be noted that 
philosophers and economists drew attention to the short-sightedness of politicians who focused on economic stability, abstracting from this stability the ensuring of social integrity (Hochman \& Rodgers, 1969; Rawls, 1971; Sen, 1979) - as seen by the social crisis caused by COVID-19.

Table 1: Musgrave's Magic Triangle in Relation to the Three Basic State Functions

\begin{tabular}{cc}
\hline Basic State Functions (possible & Explanation \\
combinations of two of three functions) & \\
\hline
\end{tabular}

Ensuring $(\boldsymbol{C})$ macroeconomic stability by The state can realise both $(\boldsymbol{C}$ and $\boldsymbol{B})$ only reducing horizontal inequality. Improving (B) social equality (justice) by reducing horizontal inequality. through fiscal consolidation to strengthen its tax base (due to the centralisation of the tax flow). However, the latter will lead to a decrease in revenue and will not allow for allocative efficiency $(\boldsymbol{A})$.

Ensuring $(A)$ allocative efficiency on the basis of strengthening the revenue autonomy of local budgets.

Achieving $(\boldsymbol{C})$ macroeconomic stability by reducing the vertical imbalance of the budget system.

Ensuring $(A)$ allocative efficiency by strengthening the revenue autonomy of local budgets.

The same fiscal policy measures lets the local governments ensure $(\boldsymbol{B})$ social justice.
Achieving $(\boldsymbol{A})$ will cause an increase in $(\boldsymbol{B})$ social inequality due to the horizontal inequality in the budget system. As a result, when $(\boldsymbol{C})$ is achieved, $(\boldsymbol{B})$ will increase.

The implementation of $(\boldsymbol{A})$ and $(\boldsymbol{B})$ can be carried out only if $(\boldsymbol{C})$ macroeconomic stability is reduced.

Source: Pilipenko, O.I., \& Pilipenko, A.I. (2020). Mysteries of unsustainable public finance and of low economic growth: trap of low efficiency of the state. In Magdalena Ziolo (Ed.), Social, Economic, and Environmental Impacts Between Sustainable Financial Systems and Financial Markets, USA: IGI Global

\section{3. "Secular Stagnation" in the 2000s and Financial Stability}

Historically, there is a tendency towards a constant slowdown in real GDP growth. This explains the fact that since the second half of the $20^{\text {th }}$ century, researchers have seriously returned to the idea of "secular stagnation" (Hansen, 1939). After the global financial crisis of 2008-9, this idea was actively discussed by economists such as Cowen (2011), Gordon (2012; 2014) and Summers (2013a; 2013b; 2014a; 2014b). Since the beginning of the 2000s, the world economy as a whole has shifted from higher growth 
rates of real GDP to lower ones (Kapeliushnikov, 2015). Over the past 20 years, this decreasing trend has consolidated across the global economy.

From 1970-85, the developed countries typically had a 3\% average annual GDP growth rate; the middle income states $4 \%$ per year and emerging markets $6 \%$. As for the average annual economic growth rate of low-income developing countries, in 2005-10 it was well above 4\%. According to the baseline development scenario by the Organisation for Economic Cooperation and Development (OECD), by 2060, the annual growth of world GDP in real terms was projected to decline to $2 \%$ (Guillemette \& Turner, 2018), provided that there were no major institutional or political changes.

This sustained decline has negatively impacted other economic indicators. For example, according to the so-called "rule 70" (Gordon, 2012; 2014), it will take about 70 years to double the per capita GDP at an annual growth rate of $1 \%$. If it rises to $2 \%: 35$ years; at 3\%: 25 years, etc. In other words, any reduction in the current indicators of economic growth turns into huge losses for society in long term quality of life. As Krugman (1994, 11) wrote: "Productivity isn't everything, but, in the long run, it is almost everything." An increase in wages and living standards is predetermined by labour productivity growth (Sneader \& Singhal, 2021).

Not surprisingly, nation-states perceived economic problems as a top priority. Real stagnating GDP growth rates directly affected the fiscal capabilities of states, since their functions were financed by state budgets, which redistributed a significant share of the current GDP. The decline in economic growth increased budget expenditures, while growing deficits were financed, as a rule, by increasing state debt. In such a situation, governments were forced to consider ensuring financial stability (Schinasi, 2006) as an unconditional priority, also predetermined by the debt policy. As a result, national governments tried to ensure financial stability through monetary and fiscal policy instruments, provided there was adequate institutional support for their implementation (Coase, 1988; Menard, 2003; Tanzi, 2011).

In this context, Summers (2014a) defined financial instability as the price paid to maintain a more or less acceptable rate of economic growth. On the eve of the COVID-19 pandemic, the state had to shoulder part of the blame for the slowdown in economic growth, having provided financial stability at the cost of ignoring the growing social "fault lines". It is this violation of the dialectic of interaction between the economy and society that led to the humanitarian catastrophe. 


\section{The Humanitarian Catastrophe}

With COVID-19, the fundamental problem was saving human lives. Below are the statistics as of 1 November 2020. Rising deaths (Figure 1) sparked active discussions on the ability of health systems to successfully fight COVID-19. According to the Johns Hopkins Coronavirus Resource Center, there was a total estimate of 217.7 million confirmed cases worldwide, with the total number of confirmed deaths estimated at over 4.52 million.

Figure 1: Dynamics of Total Cases of COVID-19, as of 1 November 2020

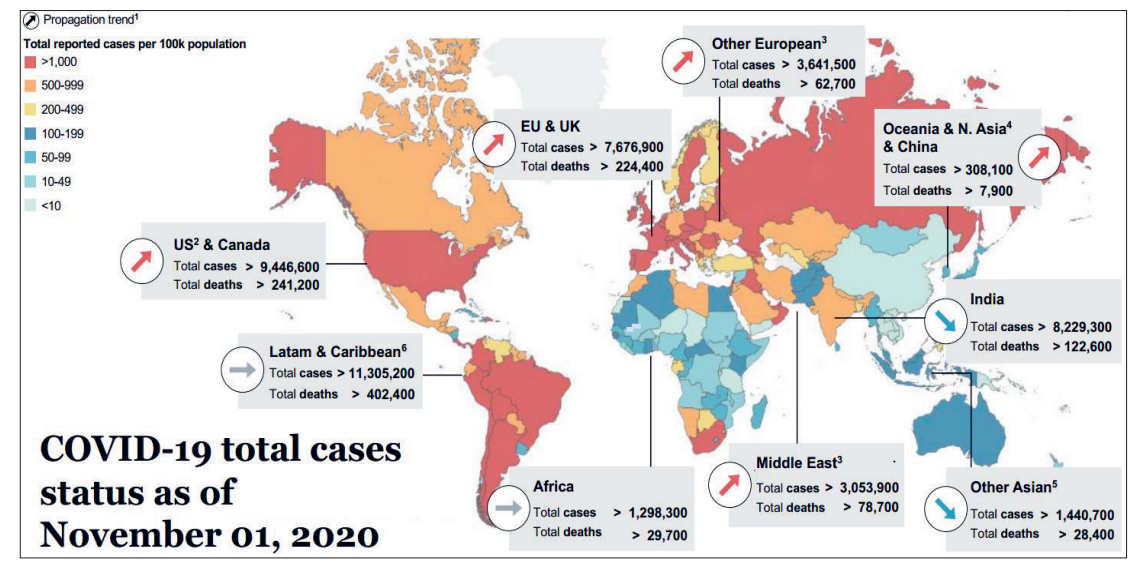

Notes:

1. Increasing ( $>10 \%$ increase in cumulative incremental cases over last 7 days, compared to incremental cases over last 8-14 days); stabilising ( 10\%); decreasing ( $>-10 \%$, if difference in incremental cumulative cases over last 8-14 days is less than 100);

2. Includes Puerto Rico and the US Virgin Islands;

3. All remaining European countries, including Russia;

4. Includes Japan, Singapore, and South Korea;

5. All remaining Asian countries, not including Russia;

6. Includes European territories in the Caribbean.

Source: COVID-19: Briefing materials (2020). Global health and crisis response. Updated 30 October. McKinsey \& Company. Mckinsey.com

The apparent ineffectiveness of national health systems has many explanations. Thus, the residual principle of financing the social functions of the state and its commitment to ensuring financial stability at any cost turned into a humanitarian catastrophe. It can be regarded as an indicator 
of missed opportunities in terms of preventing the worst of the pandemic, which immediately presented evidence of the ineffectiveness of the state's activities and pointed to the main reason for this: abstraction from the need to ensure the integrity of society as an unconditional priority of public policy. As a result, the inability of public health systems to successfully cope with life-threatening infections predetermined a societal crisis.

In fact, it manifested in such phenomena such as growing distrust of the population in the policies of nation-states, the increase in protests from citizens faced with both the problems of infection and survival during economic and social lockdowns and the loss of the foundations of material wellbeing.

Nation-states did not have a set of best practices for such a situation, so they were forced to independently develop and implement measures to combat coronavirus infection. Experts from the Boston Consulting Group (BCG) have summarised these actions and conditionally specified them in relation to three different phases of the COVID-19 pandemic: "flattening", "fighting" and "the future".

The first stage saw national governments implementing regimes to block economic activity and social communication, seeking to curb the exponential growth curve of cases. In the second phase, nation-states began to tackle infections, lifted emergency lockdown regimes and began the recovery of economic activity, balancing between maintaining low infection rates and risking new lockdowns. However, only the development and successful introduction of a vaccine or highly effective treatment marks the "future" (BCG, 2020).

Thus, the COVID-19 pandemic instantly prioritised safeguarding citizens' lives and livelihoods in the face of a humanitarian disaster. The exponential growth in the number of the cases dictated two main public priorities: (1) stabilisation of the epidemiological situation and (2) economic recovery. BCG experts called this policy an epinomic one, and identified three main strategies for states: (1) crushing and containing; (2) flattening and fighting; and (3) sustaining and supporting (Ibid.).

So, in the first two stages, nation-states balanced the needs of ensuring citizen health and minimising the economic and social costs. In this situation, most nation-states were forced to deal with the consequences of COVID-19, carrying out extraordinary budgetary expenditures to support citizens and businesses through economic and social lockdowns. According to IMF (2021), fiscal support provided by all nation states was estimated at $\$ 14$ 
trillion. These included additional budget spending or lost revenue (\$7.8 trillion), as well as equity injections, loans and guarantees ( $\$ 6$ trillion). Such fiscal expenditures were carried out during a decline in economic activity. Lower budget revenues compounded deficit increases and government debt. According to projections published in the IMF Fiscal Monitor (2019), global public debt would reach 98 per cent of GDP by the end of 2020, up from 84 per cent on the same date.

But extraordinary budgetary spending failed to prevent a humanitarian catastrophe, save lives and stop the exponential spread of infection. All this, combined with accumulated social problems in society, predetermined the decline in public confidence in the state. The Trust Index, which estimates present trust in non-governmental organisations (NGOs), businesses, governments and media in 11 countries, was 55\% in January 2020 and grew to $61 \%$ by May 2020 . However, in January 2021, the Trust Index decreased to $56 \%$. Over a period of six months, from May to January 2020, the Trust Index fell $5 \%$, with the biggest loss suffered by governments $(-8 \%)$ in January 2021, which were the most trusted institutions in May. Moreover, the greatest losses of confidence were seen in South Korea (-17), the United Kingdom (UK) (-15), China (-13), the United States (US) (-6), Germany (-5) and Japan (-1) (Edelman, 2021). This became the main barrier to the implementation of optimal strategies for the early rebuilding of economic activity.

In this context, all the above losses should be regarded as lost opportunities, as a result of the failure of the state to create national public health systems capable of efficiently preventing huge human losses. So, these missed opportunities are a direct consequence of inadequate policies of nation-states aimed at maximising economic goals by underestimating social priorities (partially connected with public healthcare systems).

\section{State Inefficiency as the Reason for Missed Opportunities}

At the end of 2019, the Economist Intelligent Unit, in cooperation with the Johns Hopkins Center for Health Security, prepared a publication titled "Building Collective Action and Accountability" (Global Health Security Index, 2019), which made it possible to assess the readiness of national health systems in protecting the lives of their citizens under extreme conditions of the spread of infections. Leaving aside the financial aspect 
of ensuring a highly effective public health system, the authors concluded that healthcare systems were in general unsatisfactory. To quote the report: "National health security is fundamentally weak around the world. No country is fully prepared for epidemics or pandemics, and every country has important gaps to address. Many countries do not show evidence of the health security capacities and capabilities that are needed to prevent, detect, and respond to significant infectious disease outbreaks" (Ibid., 12).

Experts evaluated the preparedness levels of national health systems of 195 countries and found that the overall GHS Index score average was 40.2, with 100 as the highest possible score. Among 116 high- and middleincome countries, the average GHS Index was not above 50. However, even those modest results could not assess the real state of affairs in the healthcare systems worldwide. According to Johns Hopkins University, as of 21 December 2020, the numbers of cases of infections and deaths from COVID-19 for some countries were as follows: US -17.8 million and 0.3 million respectively (GHS Index: 83.5); UK - 2.04 and 0.06 (77.9); France - 2.5 and 0.06 (68.2); Brazil - 7.2 and 0.18 (59.7); India - 10 million and 0.14 million (46.5); Russia -2.9 and 0.05 (44.3).

The data from McKinsey Global Institute (McKinsey Global Institute, 2020; 2020a) made it possible to summarise some of the above findings and to assess the missed opportunities by national communities, which were largely predetermined by a lack of understanding of the dialectics of interaction between the economy and society. Without going into deep theoretical foundations, it is reasonable to give an economic assessment in terms of the inadequate state of public healthcare. In this case, it is advisable to assess the missed opportunities from the standpoint of a state policy that would save human lives and prevent economic losses. The logic of reasoning is as follows: if health improves, then economic indicators grow due to the growth of those with good health being employed. At the same time, aggregate factor productivity increases, which makes it possible to increase social benefits, which could serve as the basis for preventing a social crisis in emergency situations. In the meantime, discussions on excessive increases in healthcare costs have been at the centre of political debates, which were not viewed as investments in the development of national communities. But from the standpoint of investing in society, healthcare financing means that this system is capable of ensuring the health of citizens through the prevention of diseases, by creating a clean and safe environment, healthier 
lifestyles, eliminating negative manifestations etc. If these conditions are met, by 2040, 230 million more people will be living on Earth, and improved health will increase the global GDP by $\$ 12$ trillion. This means an additional $8 \%$ GDP growth, or an annual increase of $0.4 \%$ (McKinsey Global Institute, 2020). One half of this annual economic growth will come from an increase in the size of the workforce and its health. The rest of GDP growth will be gained by improving the health of elderly workers and expanding the opportunities for workers with disabilities. As a result, the labour productivity of these above-mentioned workers will increase, and can be predetermined by reducing the burden of chronic diseases. At the same time, the poor health of workers reduces global GDP by 15 per cent annually (McKinsey Global Institute, 2020a). These indicators adequately assess missed opportunities of national communities that did not have highly effective healthcare systems on the eve of COVID-19.

\section{Results and Discussion}

The first result obtained is the identification of a fundamental misconception of the state, regarding the causal relationship between economic growth and financial sustainability on the one hand, and social stability on the other. Before the COVID-19 pandemic, the typical functions of the state were the institutionalisation of public goods aimed at ensuring economic equilibrium, and later financial stability. This was largely due to the fact that as economic growth fell since the last quarter of the twentieth century, the state was forced to increase budget spending, which led to chronic budget deficits and turned national governments into the largest borrowers on the financial market. As a result, they expected an unconditional improvement in the wellbeing of citizens and a strengthening of social stability. This causal relationship turned out to be a delusion, which predetermined its ineffectiveness. As a result, the state had a distorted view of social spending as a cost to society, rather than an investment in future socioeconomic progress (Goldin, 2020).

With the exponential growth of COVID-19 infections and deaths, the priority of safeguarding lives and livelihoods has come to the fore in the adoption of epinomic policies. Not by chance does the McKinsey Global Institute Report (Madgavkar et al., 2020) conclude that investing in healthcare systems can serve critical roles in future growth. Yet nothing has 
changed in public policy. Sandbu $(2020,10)$ writes that "things will never be the same. But how they will change is wide open, and policy choices made over the next few years will make a big difference to whether the post-COVID-19 world favors broadly shared prosperity more than the status quo ante."

The second result is the fact that the state turns out to be the last factor on which the construction of a new post-COVID-19 reality will largely depend. This is because the state does not have practice functioning in this uncertain reality. Waves of infections led the G20 states to announce budget packages worth more than $\$ 10$ trillion. In real terms, these fiscal expenditures were almost three times the support provided during the 2008-9 global financial crisis, and 30 times that of the fiscal support of the Marshall Plan, which rebuilt European countries after the Second World War (Madgavkar et al., 2020). For example, fiscal spending of advanced economies increased by an average of $20 \%$ of GDP in 2020, compared to 2019 . The Canadian government increased budget spending by $39 \%$ of the GDP. The US and UK, which had relatively low social spending, significantly increased their budget packages. And countries such as Denmark, which had higher social spending, did not increase these packages significantly. So, in the context of a pandemic, nation-states were forced to engage in insuring risks more intensively to society and meeting the basic needs of citizens in comparison with 2019.

However, in essence, nothing has changed. Despite the huge budgetary expenditures of the governments of developed countries, they did not solve the fundamental problem of the violation of the dialectic of relations between society and the economy. In other words, the crisis in the economy and society only worsened in the context of the pandemic (Ibid.).

The main question of post-COVID-19 reality remains open, and it is related to the extent to which nation-states will consider the new circumstances introduced by the societal crisis. In any case, the state may yet return to its typical basic functions, which aggravated the societal crisis in national communities in the first place. At the same time, it becomes evident that the pandemic has demonstrated the existence of a fundamental problem of social disunity, which can either deepen or be resolved, depending on the actions of national governments (Sandbu, 2020a).

The third result of the study is that public policy priorities will determine society's future reality. The orientation of the state towards 
structuring the post-COVID-19 reality in favour of general welfare is clearly associated with awareness of new political priorities, among which the creation of high-quality healthcare and education systems (for the purpose of reducing skill mismatches and gaps) become of top importance. However, one should agree with Martin Sandbu $(2020,9)$ that any reform programme "must be big in scope and scale-something with ambition and motivational power comparable to the New Deal or the Marshall Plan”.

\section{Empirical Evidence}

COVID-19 highlighted, simultaneously, two groups of state functions being prioritised among three traditional ones. It is about balancing preventive maintenance and safeguarding livelihoods, on the one hand, and rebuilding of the economy after lockdowns, on the other. The third group of functions relates to macroeconomic stability, without which it is impossible to reduce horizontal and vertical inequality in the long run. However, according to the logic of the triangle dilemma, this function can be realised only after the implementation of the first two groups of state functions (see Table 1). In other words, in accordance with the Musgrave uncertainty principle (Pilipenko \& Pilipenko, 2020) macroeconomic stability cannot be achieved simultaneously with the first two goals of the state's epinomic policy. It is easy to be convinced of this.

First, let us introduce the following notations:

- the first group of functions (ensuring the epidemiological situation and the survival of the population): «A»;

- the second group (rebuilding of economics after lockdown): $\langle\boldsymbol{B} »$;

- the third group (ensuring macroeconomic stability): «C».

Then the visual content of the triangle dilemma phenomenon discovered by Musgrave (1998), as analytically adequately reflects the proposed by Pilipenko (2020) principle (ratio) of uncertainty, is as follows:

$$
\Delta A \times \Delta B \times \Delta C \geq M
$$

Here, $\boldsymbol{A} \boldsymbol{A}, \boldsymbol{\Delta} \boldsymbol{B}$ and $\boldsymbol{\Delta} \boldsymbol{C}$ refer to the objective (actual) existing uncertainties of the conjugate values $\boldsymbol{A}, \boldsymbol{B}$ and $\boldsymbol{C}$. Inequality (1) expresses the inconsistency of attempts to simultaneously achieve goals and results for 
all three conjugate quantities of $\boldsymbol{A}, \boldsymbol{B}$ and $\boldsymbol{C}$, since the resulting uncertainties (and therefore risks) exceed the Musgrave constant, $\boldsymbol{M}$. In other words, these quantities are subject to natural constraints, which, as Musgrave discovered, contain inevitable uncertainties $(\boldsymbol{A} A, \boldsymbol{\Delta B}$ and $\boldsymbol{\Delta C})$. A graphic image of this triangle is shown in Figure 2 below.

Figure 2: The Musgrave Socioeconomic Triangle Dilemma.

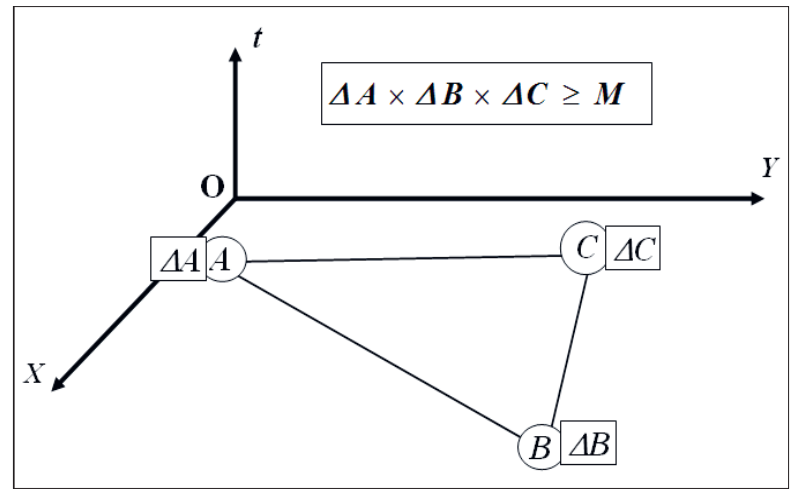

Source: Authors' own.

However, since the construction of post-COVID-19 reality is primarily associated exclusively with the preventive maintenance of the epidemiological situation and the survival of the population $(\boldsymbol{A})$ and re-building of economics after lockdowns $(\boldsymbol{B})$, then the inaccuracies or risks $(\boldsymbol{A} \boldsymbol{A}$ and $\boldsymbol{\Delta B})$ are small enough (i.e., at $\boldsymbol{\Delta A} \rightarrow \boldsymbol{0}$ and $\boldsymbol{\Delta B} \rightarrow \mathbf{0}$ ). In the calculations of characteristics, $\boldsymbol{A}$ and $\boldsymbol{B}$, there is complete uncertainty (maximum risk) of characteristic $\boldsymbol{C}$ :

$$
\Delta \boldsymbol{C} \geq\left.\frac{\boldsymbol{M}}{\boldsymbol{\Delta A} \times \boldsymbol{\Delta B}}\right|_{\substack{\Delta A \rightarrow 0 \\ \Delta B \rightarrow 0}} \rightarrow \infty
$$

In other words, no matter how attractive the idea of the simultaneous implementation of all three groups of functions may seem, it is fundamentally flawed. It brings the researcher into a high-risk area and is rejected by the Musgrave triangle dilemma.

It becomes possible to modify the model of the Musgrave socioeconomic triangle dilemma in relation to the analysis of the initial situation before constructing the post-COVID-19 reality. In the coordinate 
plane $\mathbf{X O Y}$, at the vertices of Musgrave's triangle, there are conjugated groups of functions for $(\boldsymbol{A}),(\boldsymbol{B})$ and $(\boldsymbol{C})$, which are inevitably subject to limitations in the form of uncertainties (risks) $\boldsymbol{A} \boldsymbol{A}, \boldsymbol{\Delta B}$ and $\boldsymbol{\Delta C}$. The $\mathrm{O} \boldsymbol{t}$ (time) axis is introduced to further consider the modifications of triangles in the process of sequentially resolving the dilemma at various fixed points in time $(\boldsymbol{t})$.

Figure 3 shows a scheme for constructing post-pandemic reality by consistently resolving the Musgrave triangle dilemma. Parallel to the coordinate plane, $\mathbf{X O Y}$, there is a sequence of measures to implement a programme to overcome the COVID-19 pandemic situation, in the form of Musgrave triangles. At the first stage $(\boldsymbol{t}=\mathbf{1})$, the full implementation of $\boldsymbol{A}$ and $\boldsymbol{B}$ is carried out, with a double arrow between $\boldsymbol{A}$ and $\boldsymbol{B}$. The choice of the most complete intersection $(\boldsymbol{A} \cap \boldsymbol{B})$ introduces a significant uncertainty in $\boldsymbol{A C} \rightarrow \infty$, as depicted by the symbol $\boldsymbol{C}$ in a black circle in combination with the symbol $\Delta C$. This procedure is worked out $(\boldsymbol{n}-\mathbf{1})$, i.e. $\boldsymbol{t} \in[\mathbf{1} ; \boldsymbol{n}-\mathbf{1}]$.

Figure 3: Scheme for Constructing Post-COVID-19 Reality by the Sequential Resolution of the Musgrave Triangle Dilemma

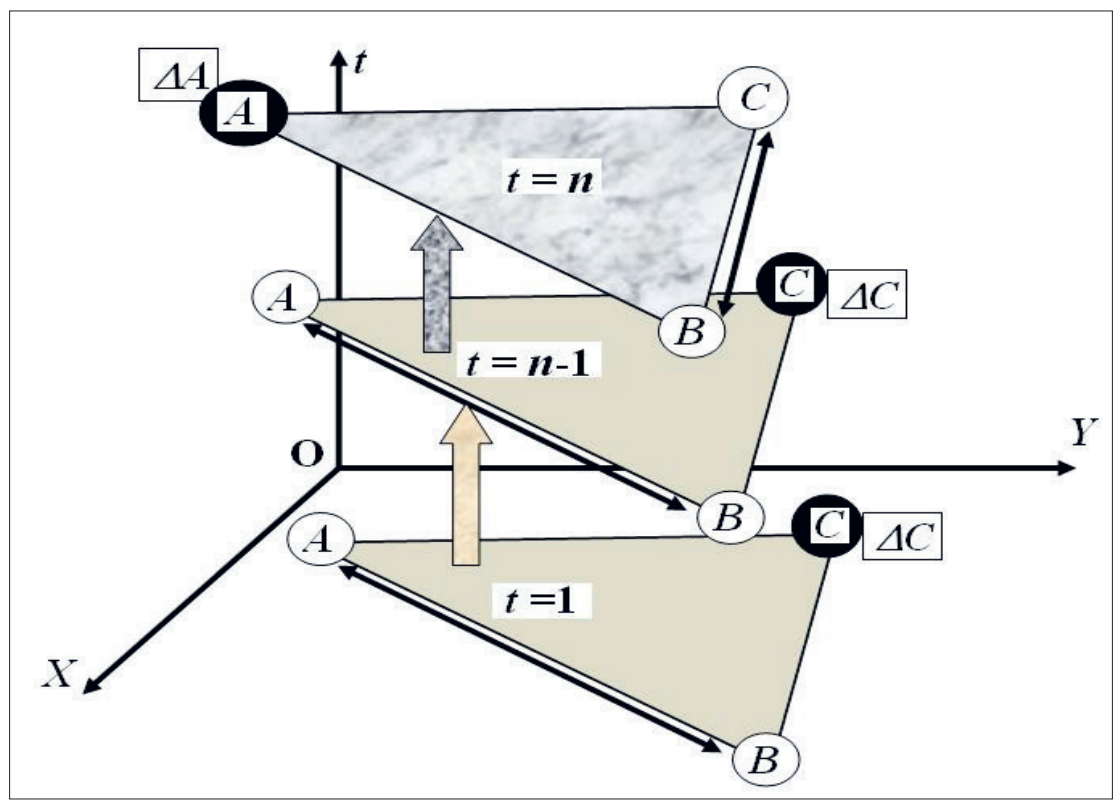

Source: Authors' own. 
In other words, Figure 3 demonstrates the sequential construction of post-pandemic reality. When acceptable results are achieved at these stages, the transition to the next stage $(\boldsymbol{t}=\boldsymbol{n})$ begins (indicated by an arrow pointing from $\boldsymbol{t}=\boldsymbol{n}-\mathbf{1}$ to $\boldsymbol{t}=\boldsymbol{n})$. At this stage, a cyclical transition is made from a paired combination of functions $(\boldsymbol{A}$ and $\boldsymbol{B})$ to a new pair $(\boldsymbol{B}$ and $\boldsymbol{C})$, as indicated by the corresponding arrow. In this case, the uncertainty $\Delta C$ is removed, but now the uncertainty $\boldsymbol{\Delta A}$ appears, which is indicated in the same way as the uncertainty $\boldsymbol{\Delta C}$ in the first stages of the construction of a new reality. Note that when a sufficiently complete realisation of the combination of $\boldsymbol{B}$ and $\boldsymbol{C}$ (due to the intersection of $\boldsymbol{B} \cap \boldsymbol{C}$ ) is achieved, a new cyclic transition is made - from the paired $\boldsymbol{B}$ and $\boldsymbol{C}$, to the stage $(\boldsymbol{t}=\boldsymbol{n}+\mathbf{1})$, to the new pair $(\boldsymbol{C}$ and $\boldsymbol{A}$ ) (not shown in Figure 3 ). The duration of the stages can be significantly reduced if it is possible to trigger the accelerator mechanism.

A big question is the readiness and ability of the state to rethink its own role and to accept the priority of societal integrity in order to achieve economic and technological progress. The presence of a political goal of achieving universal prosperity presupposes a firm intention to adequately carry out the above functions in a certain sequence and its ability to attract private business on new terms of cooperation (Vaslavskaya, 2020). The loss of confidence and the will of the state to construct an uncertain future entails many years of stagnation and regression for national communities.

\section{Conclusion}

The COVID-19 pandemic manifested itself so unexpectedly that states had to take emergency measures to protect their citizens. By resorting to regimes of social and economic exclusion to prevent the exponential growth of cases, national governments created a societal crisis. It was this phenomenon that turned out to be the main obstacle to the revival of the economy. Among other things, judging by the estimates of experts, the social and economic lockdowns predetermined unprecedented losses for society, both in terms of deaths and the reduction of national welfare in general. It should be emphasised that the COVID-19 pandemic has proven the indisputable importance of addressing social problems, which have increased even more due to the absolute decline in global GDP. The pandemic dictated a new subordination of the functions of nation-states, in which the stabilisation of the epidemiological situation came to the fore, and only after that did the 
question of timely resumption of economic activity arise.

The violation of the usual way of life, unemployment and the deterioration of wellbeing predetermined growing distrust in the actions of the state. And it should be remembered that citizens, society and the societal crisis will remain in this new world. Moreover, without the elimination of deep social rifts, there can be no further socioeconomic progress.

In this connection, there is a growing demand for a theoretical substantiation of the new functions of the nation-state, factoring in the effectiveness of formal institutions at its disposal. In this regard, the Musgrave triangle dilemma seems to be a useful theoretical construction that allows the state, if it desires, to prioritise solving the societal crisis and to functionally link the structuring of the post-COVID-19 future to common prosperity (Georgieva, 2020). COVID-19 has revealed the fundamental problem of modern socioeconomic systems - the abstraction of the state from the need to restore the dialectical interaction between society and the economy.

\section{References}

BCG. (2020). Boston Consulting Group Perspectives (2020). COVID-19: Facts, scenarios, and actions for leaders. Version 2.2. BCG. April 20. Retrieved from BCG-COVID-19-BCG Perspectives version 2.2 $20 A P R I L 2020$.

Cingano, F. (2014). Trends in income inequality and its Impact on Economic Growth. OECD Social, Employment and Migration Working Papers, No. 163. OECD Publishing. Retrieved from http://dx.doi. org/10.1787/5jxrjncwxv6j-en

Coase, R.H. (1988). The nature of the firm: origin, meaning, influence. Journal of Law, Economics \& Organization, 4(1), 33-47.

Cowen, T. (2011). The Great Stagnation: How America Ate All the LowHanging Fruit of Modern History, Got Sick, and Will (Eventually) Feel Better. New York: Penguin Group, eSpecial from Dutton.

Edelman. (2021). Edelman Trust Barometer 2021: Global Report. Retrieved from https:/www.edelman.com/sites/g/files/aatuss191/files/202101/2021-edelman-trust-barometer.pdf 
Georgieva, K. (2020). Straight talk: No going back. Investing in policies for people will help shape a better economy for the post-crisis world. Finance \& Development, 57(4), 10-2. Retrieved from https://www.imf. org/external/pubsft/fandd/2020/12/pdf/fd1220.pdf

Global Health Security Index. (2019, October 24). Building Collective Action and Accountability. The Economist Intelligence Unit. Johns Hopkins Center for Health Security.

Goldin, I. (2020). Rethinking global resilience: The pandemic is straining economic and social fault lines. Finance \& Development, 57(3), 4-10.

Gordon, R.J. (2012). Is U.S. economic growth over? Faltering innovation confronts the six headwinds. National Bureau of Economic Research Working Paper No. 18315. Cambridge. DOI 10.3386/w18315.

- (2014). The demise of U.S. economic growth: restatement, rebuttal, and reflections. National Bureau of Economic Research Working Paper No. 19895. Washington. DOI 10.3386/w19895.

Guillemette, Y., \& Turner, D. (2018). The long view: Scenarios for the world economy to 2060. OECD Economic Policy Papers. No. 22. Paris: OECD Publishing.

Hansen A.H. (1939). Economic progress and declining population growth. American Economic Review, 29(1), 1-15.

Haskel, J., \& Westlake, S. (2017). Capitalism without Capital: The Rise of the Intangible Economy. Princeton: Princeton University Press.

Hochman, H.M., \& J.D. Rodgers. (1969). Pareto optimal redistribution. American Economic Review, 59(4), 542-57.

IMF. (2019, October). Fiscal monitor: How to mitigate climate change. Washington: IMF Publication.

- (2021, January). Fiscal monitor: Government support is vital as countries race to vaccinate. Washington: IMF Publication.

IPSOS (2021). COVID-19 one year on: Global public loses confidence in institutions, IPSOS website, Retrieved from https://www.ipsos. com/en/ covid-19-one-year-global-public-loses-confidence-institutions

Kapeliushnikov, R. (2015). The idea of secular stagnation: three versions (a review article). Working Paper. WP3/2015/02. Moscow: Higher School of Economics Publishing House.

Keynes, J.M. (1936). The General Theory of Employment, Interest and Money. London: Macmillan. 
Krugman, P.R. (1994). The Age of Diminishing Expectations: U.S. economic policy in the 1990s. Cambridge, Mass: MIT Press.

Kupelian, B., \& Clarry, R. (2021). Predictions for 2021: From the great lockdown to the great rebound. Global Economy Watch. PwC. Retrieved from: https:/www.pwc.com/gx/en/research-insights/economy/globaleconomy-watch/predictions-2021.html

Madgavkar, A., Tilman T., Smit, S., \& Manyika, J. (2020, December 10). COVID-19 has revived the social contract in advanced economies-for now. What will stick once the crisis abates? McKinsey Global Institute. Retrieved from: https://www.mckinsey.com/industries/public-and-socialsector/our-insights/covid-19-has-revived-the-social-contract-in-advancedeconomies-for-now-what-will-stick-once-the-crisis-abates

McKinsey Global Institute. (2020, July). Prioritizing Health: A Prescription for Prosperity. Executive summary. Retrieved from: https://www. mckinsey.com/industries/healthcare-systems-and-services/our-insights/ prioritizing-health-a-prescription-for-prosperity

—. (2020a, July 8). Prioritizing Health: A Prescription for Prosperity. Report. Retrieved from: https://www.mckinsey.com/industries/healthcaresystems-and-services/our-insights/prioritizing-health-a-prescription-forprosperity

Menard, C. (2003). The economics of hybrid organizations. Journal of Institutional and Theoretical Economics, 160(3), 345-76.

Milanovic, B. (2019). Capitalism, Alone: The Future of the System that Rules the World. Harvard: Harvard University Press.

Musgrave, R. (1998). The role of the state in the fiscal theory. In Sorensen, P.B. (ed.), Public Finance in a Changing World (pp.35-50), London: Macmillan.

Musgrave, Richard. (1959). The Theory of Public Finance. New York: McGraw-Hill.

Okun, A.M. (2015). Equality and Efficiency: The Big Tradeoff. Washington, D.C.: Brooking Institution Press.

Pilipenko O.I., \& A. I. Pilipenko. (2020). Mysteries of unsustainable public finance and of low economic growth: trap of low efficiency of the state. In Magdalena Ziolo (Ed.). Social, Economic, and Environmental Impacts Between Sustainable Financial Systems and Financial Markets. USA: IGI Global. DOI: 10.4018/978-1-7998-1033-9.ch009 
Rajan, R.G. (2010). Fault Lines: How Hidden Fractures Still Threaten the World Economy. Princeton and Oxford: Princeton University Press.

Rawls, J. (1971). A Theory of Justice. Cambridge, MA: Belknap Press of Harvard University Press.

Sandbu, M. (2020). The post-pandemic brave new world. Policymakers' choices during this disruption could shape their economies for decades to come. Finance \& Development, 57(4), 4-10.

- (2020a). The Economics of Belonging. A Radical Plan to Win Back the Left Behind and Achieve Prosperity for All. Princeton: Princeton University Press.

Schinasi, G.J. (2006). Safeguarding Financial Stability: Theory and Practice. IMF: Washington.

Sen, Amartya. (1979). Personal utilities and public judgments; or what is wrong with welfare economics? Economic Journal, 89, 537-89.

Sneader, K., and Singhal, S. (2021). The next normal arrives: Trends that will define 2021 — and beyond. McKinsey\&Company. Retrieved from: https:/www.linkedin.com/pulse/mckinsey-next-normal-arrives-trendsdefine-2021-fullerton-msc

Summers, L. (2013a, November 9). Speech at the IMF fourteenth annual research conference. IMF Economic Forum: Policy Responses to Crises. Washington, D.C.

- (2013b). Why stagnation might prove to be the new normal. The Financial Times. 2013, December 15.

. (2014a). Reflections on the new secular stagnation hypothesis. In C. Teulings \& R.L. Baldwin, Secular Stagnation: Facts, Causes, and Cures, CEPR Press. A VoxEU.org eBook.

- (2014b). U.S. economic prospects: secular stagnation, hysteresis, and the zero lower bound. Business Economics. 49(2), 65-73.

Tanzi, V. (2011). Government versus Markets: The Changing Economic Role of the State. Cambridge: Syndicate of the Press of the University of Cambridge.

Vaslavskaya, I.Yu. (2020). PPP and financing the development of national infrastructure: safeguarding public finance sustainability. In M. Ziolo (Ed.). Social, Economic, and Environmental Impacts Between Sustainable Financial Systems and Financial Markets (pp. 261-288). USA: IGI Global. DOI: 10.4018/978-1-7998-1033-9.ch012. 